\title{
The Relationship between Teacher Perception and Support and Academic Achievement of Slow Learners in Secondary Schools in Kakamega County, Kenya
}

\author{
Wafula N. K. ${ }^{1, *}$, Bota K. N. ${ }^{1}$, Kabuka E. K. ${ }^{2}$ \\ ${ }^{1}$ Department of Educational Psychology, Masinde Muliro University of Science and Technology, Kenya \\ ${ }^{2}$ Department of Educational Psychology, Maseno University, Kenya
}

Received July 30, 2020; Revised October 4, 2020; Accepted October 24, 2020

\section{Cite This Paper in the following Citation Styles}

(a): [1] Wafula N. K., Bota K. N., Kabuka E. K. , "The Relationship between Teacher Perception and Support and Academic Achievement of Slow Learners in Secondary Schools in Kakamega County, Kenya," Universal Journal of Educational Research, Vol. 8, No. 12, pp. 6464-6472, 2020. DOI: 10.13189/ujer.2020.081211.

(b): Wafula N. K., Bota K. N., Kabuka E. K. (2020). The Relationship between Teacher Perception and Support and Academic Achievement of Slow Learners in Secondary Schools in Kakamega County, Kenya. Universal Journal of Educational Research, 8(12), 6464-6472. DOI: 10.13189/ujer.2020.081211.

Copyright $(2020$ by authors, all rights reserved. Authors agree that this article remains permanently open access under the terms of the Creative Commons Attribution License 4.0 International License

\begin{abstract}
Learning difficulties encompass a wide range of learning problems including slow learning. Slow learners have mild intellectual disability and acquire skills at a slower rate compared to the normal student. Slow learners need more explanation and demonstration to grasp concepts. However, majority of teachers tend to be frustrated by the child's inability to work at the pace of classmates. The purpose of this study was to establish the relationship between teacher perception and support, and academic achievement of slow learners in Kakamega County. Descriptive survey and correlational research designs were used. The target population was 73,985 form three and four students, 1,288 form three and four class teachers, and 12 sub-county Education Directors. Stratified random, purposive, and saturated sampling techniques were used. Fisher's formula was used to determine slow learners sample size. Questionnaires, interview schedules, and focus group discussion guides were used to collect data. The reliability coefficient index for data collection instruments was $\geq .60$. Data were analyzed using percentages, means, standard deviation, Pearson's correlation and linear regression. Findings indicated statistically significant relationship between teacher perception and support and academic achievement of slow learners in secondary schools in Kakamega County; $\mathrm{r}=0.296$. This meant that a unit improvement in teacher perception and support would result in an improvement in
\end{abstract}

academic achievement of slow learners in secondary schools in Kakamega County by $29.6 \%$. It is recommended that teachers cultivate positive perception of slow learners and accord them extra support.

Keywords Teacher Perception and Support, Slow Learner, Academic Achievement

\section{Introduction}

Learning difficulties encompass a wide range of learning problems which include poor concept formation, difficulties in acquisition of reading, writing, spelling and arithmetic skills alongside slow learning [1]. Slow learners have been described as students who learn and acquire skills at a slower rate compared to the average or normal students [1] - [3]. Williamson and Ryan [4] describe slow learners as students who have learning difficulties; implying that they may exhibit poor concept formation, difficulties in reading, writing and arithmetic skills. Slow learners struggle to grasp the curriculum, have mild intellectual disability and generally are below average cognitive abilities and scholastic performance [5] - [8]. Abosi [2] noted that the phenomenon of learning difficulties or "slow learners" is not new in Africa. The 
term refers to children who experience learning difficulties independent of obvious physical defects such as sensory disorders. This definition aptly describes the slow learner in a regular classroom setting. Such learners need special support to enhance academic achievement. However, issues related to teacher perception and support pose a risk to academic achievement of slow learners $[9,10]$.

In the recent past, society has become aware and more supportive of learners with physical challenges as evident in the concerted advocacy efforts. However, the relatively invisible mental disabilities are yet to be accorded similar support especially in developing countries. Value and focus have been attached to advocacy of rights of those with visible physical disabilities and acute mental disabilities. On the contrary, mild intellectual disabilities such as slow learning have been neglected [4]. Consequently, there is need to provide more empirical information on issues concerned with mild mental disabilities that have been neglected overtime to enhance advocacy. Silver and Bolduc [11] note that without advocacy, slow learners will continue to be sidelined yet, this type of learners face acknowledged challenges in academic performance $[7,8]$. In the spirit of inclusive education, research on the plight of slow learners in regular classes is essential.

Inclusion is the policy and practice of placing students with disabilities and special education needs in a regular class for the purpose of instruction [12,13]. The basis of Inclusion is that homes, schools and society at large should be restructured to ensure that all individuals regardless of their differences have the opportunity to interact, play, learn, work and experience the feeling of belonging and develop in accordance with their potential [14]. Implementation of Inclusive education therefore calls for the accommodation of learners with learning difficulties within regular schools and regular classrooms. However, the teaching praxis raises questions about teacher perception and support which may be a risk factor not only to the academic achievement of slow learners, but also to the successful implementation of inclusive education.

Research shows that even though slow learners have been proven to struggle in school, based on intellectual testing, they are in most cases ineligible for additional support and are generally excluded from assistance given to other learning deficit categories $[15,16]$. The absence of clear remedial policies to assist slow learners is an actual risk factor in their academic achievement. The plight of the slow learner is considered a challenge to teachers. It is noted that most teachers tend to be frustrated by the child's inability to work at the pace of their classmates [7,8]. Khan [17] has observed that slow learning children need more explanation, demonstration and experience to grasp concepts. Paul [18] has similarly observed that no significant learning can occur without a personal cordial relationship between the teacher and the learner. It is also observed that teacher support and clear consistent expectations are significantly related to levels of perceived academic competence [3,9].

In Alberta (Canada), slow learners are generally viewed as the 'dangerous others' who are likely to impede the class progress and interfere with the proper development of other students [4]. Incidentally, slow learners are commonly labeled as unteachable, hard to teach, lazy, difficult, careless and stupid or foolish [1,19]. This implies a predominant negative perception by teachers which may be a risk factor to the academic achievement of learners with learning difficulties. The teacher's perception of the slow learner therefore emerges as a key factor in the slow learner's success in school. Metto and Makewa [20] observed that teachers tend to rush over lessons interacting only with the bright students ignoring the weak and slow learners.

Furthermore, the education system in Kenya is result oriented. Exam results are viewed as a parameter of efficiency and effectiveness in the teaching and learning activities in school. Value is therefore attached to the mean score and position in the school ranking at national, regional and local levels [21]. This perspective has jeopardized slow learners' retention and completion in schools, because of the low grades and general poor academic performance. As a result, some may be coerced to repeat the class, with others opting to drop out of school [22].

Mwangi [23] observed that in Kenya, slow learners are rarely identified for proper placement and provision. In essence, the slow learners are in regular schools and classrooms where they are referred to as unteachable, hard to teach, lazy, strugglers, difficult, careless and stupid $[1,19]$. These learners face myriad risk factors that may predispose low scores on standardized tests, class repetition and in extreme cases dropping out of school. The outlined views raise concern about the relationship between teacher perception and support and academic achievement of slow learners in secondary schools. It has been observed that teachers' perception and support are critical in influencing learning of children with learning difficulties [24,25]. The research question to be addressed in this paper is whether there is a relationship between teacher perception and support and academic achievement of slow learners in secondary schools in Kakamega County, Kenya.

\section{Teacher Perception and Support and Academic Achievement}

Generally, teachers' beliefs, practices and attitudes are important for understanding and improving educational processes [9]. Teachers are the key implementers of the academic curriculum in schools and in the process they inevitably interact with slow learners. Research has shown that negative perception can lead to low expectations of a 
person [26]. On the other hand, positive perception can lead to higher expectations of a person [27]. The influence of teacher perception on a learner's performance is considered significant. For instance, negative attitudes and low expectations by teachers can result in reduced opportunities for students to learn and impair students' self-beliefs. However, positive perception can enhance prospects for students to learn, which may improve their performances, self-expectations and self- esteem [26,28]. The argument advanced is that when learners perceive that the teachers expect them to fail, they may inevitably fail. However, if the learners perceive that the teachers expect them to pass; they are likely to work hard in order to fulfill the teachers' expectations. This implies that teacher's perception and support are likely to influence the learner's personal study efforts including individual consultation with subject teachers. Therefore, it is critical that teachers have positive perception of students [9], [27], [29]. Notably, teachers with good interpersonal skills who not only address the cognitive abilities of the learners but also their feelings subsequently influence their academic achievement. A positive and courteous relationship between teacher and student is deemed an important classroom factor in promoting academic achievement.

Hattie [30] explored the extent to which student-teacher relations affected student educational investment and academic achievement. Results revealed that student-teacher relationship had a significant positive influence on a student's ability to make informed educational investment which directly impacts academic success. It was observed that person-centered teachers facilitate self-respect and higher academic achievement. Empathy, love, cooperation, competence, patience and calmness are considered ideal characteristics to be exhibited by the teacher [31]. Friend and Gately [32] and Contreras [9] observe that teachers are the main source of motivation for a student noting that the dismissive attitude of some teachers may discourage active participation of students in class discussions which is an impediment to academic achievement. Silver and Bolduc [11] further observe that punitive systems are rarely beneficial to the slow learner and in most cases only strain teacher-student relationships.

Ogadho [25] noted that apart from teacher training level and professional qualifications, the attitude of the teacher was critical in influencing learning of pupils with learning difficulties. The study undertaken in Kisumu East primary schools indicated that $72 \%$ of the respondents felt that teacher attitude influenced the dropout rate of pupils with learning difficulties to a large extent. This underlines the importance of teacher perception in learning outcomes. Fakolade, Adeniyi and Tella [33] and Ogadho [25] further observe that the patience of a teacher and willingness to go an extra mile for the learner may be of assistance to the slow learner. Paul [18] emphasized the need for teachers to make the learner feel wanted and needed despite the presumed failure to meet class and family expectations. The argument is that teachers should be on the forefront of moderating the parents' expectations based on their perception, skills and knowledge of slow learners. Research highlights the importance of teacher-student relationship; Lee [34] found a positive and significant relationship between the student's sense of trust and academic achievement. The study undertaken in South Korea depicted that students who perceived approval from their teachers were highly motivated to achieve. By inference, perception of a supportive relationship with the teacher motivates the learner to be successful in school. Lee further argued that students' perception of supportive teachers enabled students to feel a strong sense of belonging and facilitated success at school.

This paper argues that close interaction with the learner ought to equip the teacher with the right perspective of the slow learner. Furthermore, with relevant knowledge about achievement level and appropriate strategies to assist the slow learner, the teacher should offer requisite support. Williamson and Ryan [4] emphasize the need for teachers to moderate parents' expectations and dissuade the parents from putting undue pressure on the learners. Essentially, the teacher is better placed to guide and counsel both the learner and parent. However, this is only attainable if teachers have a favorable perception of slow learners. Researchers have tended to focus on the practice of teachers neglecting their philosophy and beliefs about the children they teach. Incidentally, Gutman and Eccles [39] argue that secondary school settings do not support children's development because they are characterized by less supportive teachers. They observed that teachers in high school have more negative attitudes towards students and most harbor a belief that academic abilities cannot be changed by class instructions. Furthermore; Rice, Barth, Guadagno, Smith \& McCallum [36] argue that there is a general decrease in teacher support to the learner at high school level. They further note a tendency of high school teachers having more negative attitude towards students with learning difficulties. Woodcock [37] found that secondary school trainee teachers had the least positive attitude towards students with Specific Learning Disabilities (SLD) compared to their primary school counterparts. Teachers as the key facilitators of the learning process inevitably interact with slow learners at secondary school level. Their perception and support of the slow learner is therefore a possible determinant of the learner's academic achievement. Positive teacher perception and support may herald greater academic success while negative perception and low support may be a risk to the slow learner's academic achievement.

Erkman et al. [38] examined the influence of perceived teacher acceptance on academic achievement of school age children in Turkey. The findings indicated a significant correlation between perceived teacher acceptance and academic achievement of boys $(r=0.27, p<0.05)$. 
However, the correlation was insignificant among girls $(r$ $=0.19,>0.05)$. Regression analysis similarly portrayed that perceived teacher acceptance was a significant predictor of boys' academic achievement. The inference drawn is that students are likely to achieve when they feel warmth, empathy and positive reinforcement from teachers. Conversely, lack of warmth and empathy from teachers is likely to result in lower academic achievement. The importance of teacher support is illustrated [39]. A study undertaken in Hong Kong found that perceived teacher support is significantly and positively related to academic achievement $\left(E_{d}=0.34, p<0.05\right)$. Similarly, research on perceived social support and early adolescent achievement in Turkey [40] indicated significant correlation between teacher support and math achievement $(r=0.43, p<0.01)$. Rice et al. [36] also established a relationship between teacher support and self-efficacy in math and science. Their study yielded a correlation index of .29 and .26 between teacher support and math and science self-efficacy respectively. These studies however focused on the general student population. In the light of these facts, this study sought to establish the relationship between teacher perception and support and the academic achievement of slow learners at secondary school level.

\section{Research Methodology}

The study used descriptive survey and correlational design because the intent was to establish the relationship between perceived teacher perception and support and academic achievement of slow learners. Descriptive survey method allows the collection of both qualitative and quantitative data. The design is fairly economical and allows the collection of information from a large population at a minimal cost [41, 42]. Correlational research design was used to determine the relationship between teacher perception and support and academic achievement. The target population was 73, 985 students (36,453 form three and 37, 352 form four), 1,288 form three and four class teachers and 12 Ministry of Education sub-County Directors of Education.

Stratified random sampling was used to select the schools because they were not homogenous [43]. The strata consisted of schools based on the school type (sub-county, county, extra county and national). Saturated sampling was used in selecting the national schools. This study adopted a ten percent sample size drawn from the target population. A sample of 35 schools was selected, alongside 129 class teachers and 2 Sub-County Directors of Education. Fisher's formula was used to determine the appropriate sample for slow learners because the exact population was not known. The slow learners sample was therefore 246. From each selected school, slow learners were selected from the last ten students in form four and three based on achievement tests. Teacher nomination was also key in identification of slow learners to participate in the study. The data analysis was done using the Statistical Package for Social Sciences (SPSS) version 22. Percentages were used to show the proportion of the respondents who indicated always, occasionally and never at all, based on the teacher perception and support scale (table 1). The mean and standard deviation were computed based on the 3-point Likert scale. The lowest score was 1 and the highest score 3. Pearson's $r$ correlation coefficient and simple linear regression were computed based on the teacher perception and support scale scores and average scores for English and mathematics tests to determine the relationship between teacher perception and support and academic achievement of slow learners.

\section{Results and Discussion}

The study sought to test the null hypothesis that there is no significant relationship between teacher perception and support and the academic achievement of slow learners in secondary schools in Kakamega County, Kenya. The respondents were initially asked to rate their teachers' perception and support measured on a 3-point Likert Scale and the results are provided in table 1 .

From the data in table 1, it is indicated that majority of the teachers $(49 \%)$ occasionally appreciate students' academic efforts. However, $12 \%$ never appreciated the learners' efforts. According to the findings, $52 \%$ of the respondents did not view their teachers' comments as hurting. On the other hand, $37 \%$ claimed that their respective teachers occasionally make hurting comments about their academic performance. Majority of the respondents $(63 \%)$ felt that teachers' comments on their report cards were not discouraging, but a considerable portion $(37 \%)$ observed that the teachers' comments were discouraging. This implies that while most respondents perceive a favorable perception by their teachers, some of them felt that their teachers have an unfavorable perception. It is worth noting that most of the teachers showed a personal concern about students' academic performance as indicated by $61 \%$ of the respondents. Similarly, $78 \%$ and $75 \%$ of the respondents claim that their respective teachers are always friendly and encourage them about classwork and always care about their class performance respectively. It is also noted that $81 \%$ and $76 \%$ of the respondents claimed that they had never felt that their teachers had given up on them nor neglected by the teachers respectively. Based on the findings, the average satisfaction level of the students about their teachers' support and perception was $86 \%$ (Mean $=2.5927$, Std. dev . $=0.33248$ ) as shown in table 1 . It is an indication that majority of the slow learners in secondary schools in Kakamega county perceive their respective teachers as supportive and have favourable perception. 
Table 1. Descriptive statistics for Teacher perception and support of slow learners. $1=$ Never at all, $2=$ Occasionally, $3=$ Always

\begin{tabular}{|c|c|c|c|c|c|c|}
\hline $\begin{array}{l}\text { My teachers appreciate my } \\
\text { academic efforts }\end{array}$ & \multicolumn{2}{|c|}{$39 \%$} & \multicolumn{2}{|c|}{$49 \%$} & \multicolumn{2}{|c|}{$12 \%$} \\
\hline Statement & \multicolumn{2}{|c|}{ Always } & \multicolumn{2}{|c|}{ Occasionally } & \multicolumn{2}{|c|}{ Never at all } \\
\hline $\begin{array}{c}\text { My teachers make hurting } \\
\text { comments about my academic } \\
\text { performance }\end{array}$ & \multicolumn{2}{|c|}{$11 \%$} & \multicolumn{2}{|c|}{$37 \%$} & \multicolumn{2}{|c|}{$52 \%$} \\
\hline $\begin{array}{l}\text { The teachers' comments in my } \\
\text { report book discourage me }\end{array}$ & \multicolumn{2}{|c|}{$16 \%$} & \multicolumn{2}{|c|}{$21 \%$} & \multicolumn{2}{|c|}{$63 \%$} \\
\hline $\begin{array}{c}\text { My teachers show a personal } \\
\text { concern about my academic } \\
\text { performance }\end{array}$ & \multicolumn{2}{|c|}{$61 \%$} & \multicolumn{2}{|c|}{$34 \%$} & \multicolumn{2}{|c|}{$5 \%$} \\
\hline $\begin{array}{c}\text { My teachers are friendly and } \\
\text { encourage me about my class } \\
\text { work }\end{array}$ & \multicolumn{2}{|c|}{$78 \%$} & \multicolumn{2}{|c|}{$20 \%$} & \multicolumn{2}{|c|}{$2 \%$} \\
\hline $\begin{array}{l}\text { I feel that my teachers care } \\
\text { about my class performance }\end{array}$ & \multicolumn{2}{|c|}{$75 \%$} & \multicolumn{2}{|c|}{$21 \%$} & \multicolumn{2}{|c|}{$4 \%$} \\
\hline $\begin{array}{l}\text { I feel that my teachers have } \\
\text { given up on me }\end{array}$ & \multicolumn{2}{|c|}{$3 \%$} & \multicolumn{2}{|c|}{$15 \%$} & \multicolumn{2}{|c|}{$81 \%$} \\
\hline I feel neglected by my teachers & \multicolumn{2}{|c|}{$3 \%$} & \multicolumn{2}{|c|}{$21 \%$} & \multicolumn{2}{|c|}{$76 \%$} \\
\hline \multirow{2}{*}{$\begin{array}{c}\text { Average satisfaction level in } \\
\text { support }\end{array}$} & Mean & $\%$ Mean & Std.dev & Std. Error & Min. & Max. \\
\hline & 2.5927 & $86 \%$ & .33248 & .02178 & 1.63 & 3.00 \\
\hline
\end{tabular}

The questionnaire findings are corroborated by the focus group discussions. Most of the learners portrayed a favourable view of their teachers' perception and support. However, a few of them felt that teachers ought to be more approachable and should strive to make the staff room more learner friendly to encourage extra consultations. It emerged that in some schools the staff room is out of bounds for students, while in other schools students can only talk to the teachers through the staff room window which the respondents felt was demeaning. Furthermore, some teachers have a tendency of delivering a stream of condemnations as students enter the staff room; for example, "Hey you! Where is your tie", "Look at your skirt", Those are not school shoes come here!". The overall effect is that the slow learners eventually avoid personal consultations with specific subject teachers, which adversely affects their academic achievement. The learners requested that teachers should be more accommodating.

Similarly, interviews with the class teachers indicated that some teachers considered the slow learners a bother because they lowered the subject mean. Comments such as "these ones are just for justifying my salary", "going to that class or not going amounts to the same thing'” typify the underlying negative perception of slow learners by some teachers. One student describing the form four revision programmes noted "tunadividiwa kwa madarasa ya werevu na wajinga" which translates into "we are divided into classes for the clever and stupid". The student further noted that teachers normally require an incentive (money) to go to the designated "stupid" class. This is an indicator that slow learners are aware that some teachers have a negative perception and are reluctant to give extra support. Notably, Contreras [9] observed that the dismissive attitudes of some teachers discourage learners from actively participating in class activities; hence, limiting learners' academic achievement.

Furthermore, Biggs [44] emphasizes that the teacher as a facilitator needs to create a learning environment by encouraging and supporting the learner. Paul [18] similarly observed that no significant learning can occur without a personal cordial relationship between the teacher and the learner. The view is supported by other researchers who note that teacher support and clear consistent expectations of behavior are significantly related to levels of perceived academic competence [3,9]. Additionally, Contreras [9] stressed that students in a caring learning environment perform better on standardized tests than students in a less caring environment. Also, teachers' attitude was depicted to influence the dropout rate of pupils with learning difficulties in the study undertaken in Kisumu East Sub County [25]. This underlines the postulation that inadequate support from teachers and unfavorable teacher perception are detrimental to slow learners' academic achievement.

The current study established that most of the learners view their teachers as caring $(75 \%)$ and friendly $(78 \%)$ and notably only $2 \%$ indicated that they have ever felt like dropping out of school. This supports the argument that teachers' provision of a caring and friendly environment reduces disengagement towards school [39]. However, based on the findings, teachers need to appreciate the efforts exhibited by slow learners more since only $49 \%$ of the respondents indicated occasional appreciation from teachers and $12 \%$ felt that the teachers never appreciate their academic efforts. Teachers should also desist from making hurting comments as indicated by the responses; $11 \%$ responded always and $37 \%$ occasionally in relation to 
teachers making hurting comments. The importance of positive comments by teachers was underlined by teachers' questionnaire; $52.5 \%$ and $41.0 \%$ indicated that positive comments by teachers will positively influence academic achievement of the slow learner in secondary schools to a very large extent and large extent respectively. Incidentally, $80.3 \%$ of the teachers felt that negative teacher perception will negatively influence the academic achievement of slow learners. It can therefore be concluded that based on the study, most slow learners feel their teachers perceive them favourably and give them support. However, there are a few teachers who clearly have a negative perception and withhold support hence, the need for advocacy and capacity building in helping slow learners.

The study administered a standard test for English and Mathematics across all the sampled schools. These standard tests were meant to assess the current academic performance of the students and the results are in Table 2.

Table 2. Performance in the Standard Tests

\begin{tabular}{ccccc}
\hline & Mean & $\begin{array}{c}\text { Std. } \\
\text { Deviation }\end{array}$ & Minimum & Maximum \\
\hline $\begin{array}{c}\text { Mathematics } \\
\text { (Percentage) } \\
\text { English } \\
\text { (Percentage) }\end{array}$ & $37.98 \%$ & 11.549 & 0 & 100 \\
$\begin{array}{c}\text { Average academic } \\
\text { Achievement }\end{array}$ & $42.00 \%$ & 19.494 & 0 & 100 \\
\hline
\end{tabular}

The findings of the standard tests as shown in table 2 indicate that the sampled students' academic performance is below average. The mean score for the mathematics test was $37.98 \%$ (Mean score $=$

$37.98 \%$, Std. dev. $=11.549)$ and that for the English test was $48 \%$ (Mean score $=48 \%$, Std. dev. $=19.494)$. The average academic achievement score was $42.89 \%$ (Mean score $=42.89 \%$, Std. dev. $=21.88217)$. This was below the standard average performance of $50 \%$ thus indicating that majority of the slow learners in secondary schools in Kakamega county have below average academic performance.

This confirms the assertions that slow learners struggle to grasp the curriculum, have mild intellectual disability and generally below average cognitive abilities and scholastic performance [2], [5], [7], [8]. Qian [6] similarly argued that slow learners are low achievers, have low power of retention and memory, poor organization and low academic success. The outcome in the tests therefore suggests that the respondents have learning difficulties as depicted by low academic achievement. This is evident in the mean scores in the mathematics test $(37.98 \%)$ and English mean score (48\%) and average mean of (42.89\%).

To test the null hypothesis that there is no significant relationship between teacher perception and support and the academic achievement of slow learners in secondary schools in Kakamega County, the study used Simple Linear Regression analysis. Results were as shown in Table 3 .

Table 3. Linear Regression Analysis between Teacher Perception and Support and Academic Achievement of Slow learners in Secondary Schools in Kakamega County.

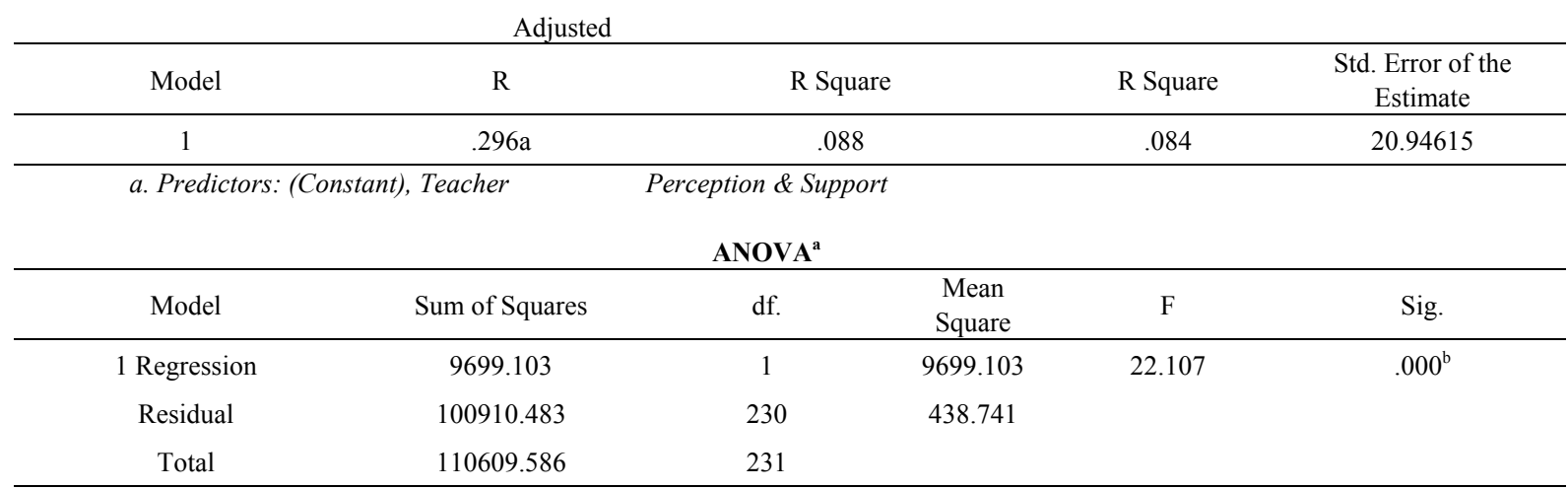

a. Dependent Variable: Academic Achievement

b. Predictors: (Constant), Teacher Perception \& Support

\begin{tabular}{|c|c|c|c|c|c|}
\hline \multicolumn{6}{|c|}{ Coefficients $^{\mathrm{a}}$} \\
\hline & & \multicolumn{2}{|c|}{ Unstandardized Coefficients } & \multirow{2}{*}{$\frac{\text { Standardized }}{\text { Std. }}$} & \multirow[t]{2}{*}{ Coefficients } \\
\hline & & & & & \\
\hline Model & Error & Beta & $\mathrm{T}$ & Sig. & \\
\hline 1 (Constant) & -7.588 & 10.823 & -.701 & .484 & \\
\hline Teacher Perception \& Support & 19.477 & 4.143 & .296 & 4.702 & .000 \\
\hline
\end{tabular}

a. Dependent Variable: Academic Achievement 
Results for the ANOVA test as shown in Table 3 were $\mathrm{F}$ $(1,230)=22.107, \mathrm{P}=0.000<0.05$; this indicates that the adopted linear regression model was a good fit to the study data set. The model (Teacher perception and support) was able to explain $8.4 \%$ of the variation in the academic achievement of the slow learner students in secondary schools in Kakamega County as indicated by the Adjusted $\mathrm{R}$ Square $=0.084$ as shown in the model summary of Table 3 . The regression Coefficient results showed that

$\beta=19.477, t=4.702, p=0.000<0.05$; therefore, the study rejected the null hypothesis and concluded that Teacher perception and support has a statistically significant influence on the academic achievement of the slow learner students in secondary schools in Kakamega county. Teacher perception and support had a positive standardized beta coefficient $=0.296$ as shown in the coefficient results of Table 3. This indicates that a unit improvement in the Teacher perception and support was likely to result in an improvement in the academic achievement of the slow learner students in secondary schools in Kakamega County by $29.6 \%$.

The findings support the importance of favorable teacher perception and support and the assertion that teachers must create a learning environment that facilitates learning outcomes [44]. It is also in line with the declaration that the teacher as a personal trainer encourages and supports the learner to attain the academic goals [45]. The current study findings indicate that favorable perception and concerted support from teachers will improve academic achievement of slow learners in secondary schools. Teachers therefore ought to be encouraged to cultivate a positive perception of slow learners and to increase the support accorded to students with learning difficulties.

\section{Conclusions}

The study examined the relationship between teacher perception and support and academic achievement of slow learners. Based on the findings, the following conclusions were made:

i The null hypothesis postulating no significant relationship between teacher perception and support and academic achievement of slow learners in secondary school is rejected. The study findings indicate a statistically significant relationship between teacher perception and support and academic achievement of slow learners; $r=0.296$.

ii A unit improvement in teacher perception and support will lead to an improvement in academic achievement of slow learners in secondary schools in Kakamega County by $29.6 \%$.

iii Positive teacher perception and support is associated with better academic achievement while negative teacher perception and support is associated with lower academic achievement.
Based on the conclusions, the following recommendations were made:

i Teachers ought to appreciate every minimal effort and slight improvement exhibited by the slow learner, which encourages and sustains the efforts of the struggling student. Furthermore, any support provided is instrumental in bringing about academic improvement no matter how slight. Clearly, the students place a lot of value on the teachers' perception and support.

ii Teachers ought to give both public and private compliments to the struggling students, which motivates them to work hard.

iii Teachers should desist from making humiliating or demeaning statements about the slow learners.

iv Workshops should be held in order to sensitize teachers on influence of teachers' perception and support on the academic achievement of slow learners.

The study used a cross-sectional study design which is a limitation in the accurate determination of cause and effect. It is therefore recommended that future research employ longitudinal study design.

\section{REFERENCES}

[1] Ndani, M. \& Murugami, M. (2009). Children in Need of Special Protection. Nairobi, Kenya: Longhorn.

[2] Abosi, O. (2007). Educating Children with Learning Disabilities in Africa. Learning Disabilities Research and Practice. 22(3). 196-201. DOI: 10.1111/j.1540-5826.2007. 00242.x

[3] Sebastian. (2016). Ensuring Learning in Slow Learners. International Journal of Education and Applied Social Sciences. 17(2).

[4] Williamson, J, \& Ryan, P. J. (2012). The "Slow Learner" as a mediated Construct. Canadian Journal of Disabilities Studies. www.cjds.uwaterloo.cas

[5] Reynolds, C., \& Fletcher-Janzen, E. (2006). Encyclopedia of Special Education. A Reference for children, adolescents and Adults with Disabilities and other Exceptional Individuals. Hoboken: John Wiley and Sons.

[6] Qian, J. (2008). English Classroom Interaction between Slow Learners and Teachers. A Case study of Slow learners at Primary Level in Suzhou District, China. Unpublished Master's Thesis. University of Oslo.

[7] Borah, R. R. (2013). Slow Learners: Role of Teachers and Guardians in Honing their Hidden Skills. International Journal of Educational Planning and Administration, 3(2), 139-143.

[8] Vasudevan, A. (2017). Slow Learners-Causes, Problems and Educational Programmes. International Journal of Applied Research, 3(12): 308-313. 
[9] Contreras, E. M (2011). The Effects of Teacher Perception and Expectations on student Achievement. https://escholarships.org/uc/item/1b84k07z

[10] Mirani, S., \& Chunawala, S. (2016). Teachers Perception of dealing with mixed Ability Classrooms. https//www.researc hgate.net/publications/292513387

[11] Silver, F., \& Bolduc, R. (2013). Supporting Slow learners and Students with MID: Building Academic and MetaAcademic Resilience. OECTA PD. Ottawa Catholic Schools Board.

[12] Lerner, J., \& Kline, F. (2006). Learning Disabilities and Related Disorders. Characteristics and teaching Strategies. Boston: Houghton Mifflin.

[13] Zigler, R., Lusweti, S., Macmbinji, V., Jumba, V., Kaggi, B., \&Namirembe, B (2017). Situational Analysis and Development of Inclusive Education in Kenya and Tanzania. The journal of the international Association of Special Education, 11791), 11-26.

[14] MoE, (2018). Education and Training Sector Policy for Learners and Trainees with Disabilities.

[15] Claypool, J., Murusiak, C., \& Janzen, H. (2008). Ability and Achievement Variables in Average, Low Average and Borderline Students, Alberta Journal of Educational Research, 54(4), 432-447

[16] Alberta Education. (2010). Special Education Coding Criteria. Edmonton: Crown in Right of Alberta.

[17] Khan, S. M. (2008). Education of Slow Learners. Retrieved 2016. http://research education

[18] Paul, B. P. (2016). Coping with Slow Learners. International Journal of Management and Applied Science. ISSN:23947926. 2(12), 56-58.

[19] Rasugu, O. G. (2010). Nature and prevalence of learning disabilities among standard three primary school pupils in Starehe Division, Nairobi Province, Kenya. Unpublished Master's Thesis, Kenyatta University.

[20] Metto, E., \& Makewa, N. L. (2014). "Learner-centered Teaching: Can It work in Kenya Public Primary Schools". American Journal of Educational Research, 2-11A, 23-29. doi: 10.12691/education

[21] Wanyonyi, W.N. (2010). The perception of an Effective School. Western province Elimu Newsletter (14), 48-49.

[22] Bota, K. N. (2007). Grade Repetition in Kenyan Primary Schools: Issues of Learning Disabilities. NJ: Transaction.

[23] Mwangi, L. (2013). Special Needs Education (SNE) in Kenyan Public Primary Schools: exploring government policy and teachers understanding (Doctoral thesis, The University of Brunel, London, England). Retrieved from http: bura.brunel.ac.uk/bistream/2438/7767

[24] Kirk, S. A., Anastasiow, N. J., Gallagher, J. J., \& Coleman, M. R. (2006). Exceptional Children. New York: Mafflin.

[25] Ogadho, W. A. (2012). Factors Influencing Drop Out among Learners with Learning Disabilities in Regular Primary Schools in Kisumu East District, Kenya. Unpublished Master's Thesis, Maseno University.

[26] Palmer, D. (2006). Durability of Changes in Self-Efficacy of
Preservice Primary Teachers. International Journal of Science Education, 28(6), 655-171.

[27] Angelides, P. (2008). Patterns of Inclusive Education through the Practice of Student Teachers. International Journal of Inclusive Education, 12(3), 317-329.

[28] Woolfson, L., Grant, E., Campbell, L. (2007). A Comparison of Special, General and Support Teachers' Controllability and Stability Attributions for Children's Difficulties in Learning. Educational Psychology, 27(2), 295-306.

[29] Winter, E. (2006). Initial Teacher Education: Preparing New Teachers for Inclusive Schools and Classrooms. Support for Learning, 21(2), 85-91.

[30] Hattie, J. (2009). Visible Learning: A Synthesis of over 800 meta-analyses relating to achievement. Abingdon: Routledge.

[31] Lerner. (2004). Preschool Children with Special Needs. Boston: Allyn \& Bacon.

[32] Friend, M., \& Gately, L. (2003). Interactive Collaborative Skills for School Professionals. New York: Longman.

[33] Fakolade, A. O, Adeniyi, S. O \& Tella, A. (2009). Attitudes of Teachers towards the Inclusion of Special Needs Children in General Education Classroom: The Case of Teachers in Some Selected Schools in Nigeria. International Electronic Journal of Elementary Education. 1(3)

[34] Lee, S-K, (2007). The Relations between Student-Teacher Trust Relationship and School Success in the Case of Korean Middle Schools. Educational Studies 33(2):209-216.Doi: 1080/03055690601068477.

[35] Gutman, L. M., \& Eccles, J. S. (2007). Stage-Environment Fit during Adolescence: Trajectories

[36] Rice, L., Barth, M. J., Guadagno, E. R., Smith, A. P. G., McMallum, M. D (2013). The Role of Social Support in Students Perceived Abilities and Attitudes towards Math and Science. J Youth Adolescence. 42: 1023-1040. DOI 10.0007/s 10964-012-9801-8

[37] Woodcock, S. (2013). Trainee Teachers' Attitudes towards Students with Specific Learning Disabilities. Australian Journal of Teacher Education, 38 (8), 15-29.

[38] Erkman, F., Caner, A., Sart, Z. H., Borkan, B., \& Sahan, K. (2010). Influence of Perceived Teacher Acceptance, Self-concept and School Attitude on the Academic Achievement of School-Age Children in Turkey. Sage Journals. https://doi.org/10.1177/10693971103666.

[39] Chen, J. J. (2008). Grade level Differences: Relations of Parental, Teacher and Peer support to academic Engagement and Achievement Among Hong Kong students. School Psychology International. Vol 29(x): 000-000. Doi:10117/01430343080xxxxx

[40] Ahmed, W., Minnaert, A., Van der Werf, G., \& Kuyper, H. (2010). Perceived social support and early adolescents' achievement: the mediational roles of motivational beliefs and emotions. Journal of Youth and Adolescence, 39, 36-46

[41] Punch, K.F., \& Oancea, A. (2014). Introduction to Research Methods in Education. 2ne Ed. Sage Publications. New Delhi. 
and Academic Achievement of Slow Learners in Secondary Schools in Kakamega County, Kenya

[42] Mertler. C. A. (2019). Introduction to Educational Research. $2^{\text {nd }}$ Ed. New Delhi: Sage publications.

[43] Kothari, C. R., (2004). Research Methodology: Methods \& Techniques. New Delhi, India: New Age International.

[44] Biggs, J. (2011). Aligning Teaching for Constructing
Learning. The Higher Education Academy, YorkUnitedKingdom.http://ww,leaacdaemy.ac.uk/assets/do cuments/resources/resourcedatabase/11477

[45] Bye, R. (2017). The Teacher as Facilitator for Learning Flipped Classroom in a Master's course on Artificial Intelligence. DOI: 10.5220/0006378601840195 